\title{
Soil Inoculation with Cyanobacteria: Reviewing Its' Potential for Agriculture Sustainability in Drylands
}

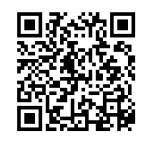

\author{
Sonia Chamizo ${ }^{1 *}$, Emilio Rodríguez-Caballero ${ }^{2}$, Yolanda Cantón ${ }^{3}$ and Roberto De Philippis ${ }^{1}$ \\ ${ }^{1}$ Department of Agrifood Production and Environmental Sciences (DISPAA), University of Florence, Italy \\ ${ }^{2}$ Estación Experimental de Zonas Áridas, CSIC, Spain
}

${ }^{3}$ Department of Agronomy, University of Almería, Spain

Submission: June 18, 2018, Published: September 28, 2018

"Corresponding author: Sonia Chamizo, Department of Agrifood Production and Environmental Sciences (DISPAA), University of Florence, Via Maragliano 77; I-50144 Firenze, Italy; Tel: 00393404145176; Email: sonia.chamizodelapiedra@unifi.it

\begin{abstract}
In the last decades, there has been a huge expansion of intensive agriculture crops to attend the enormous demand of food needs with increasing population. Intensive agriculture is highly dependent on chemicals, which has caused numerous environmental problems such as contamination of aquifers, soils and air, with serious consequences on human health. A challenge in the next decades will be the development of economically viable methods to enhance productivity, at the same time that conservation of natural resources, protection of environment and production of healthy agricultural products are ensured. Sustainable agriculture requires management of a healthy living soil. Use of microorganisms such as cyanobacteria appears as a real alternative to achieve more sustainable managements. In this review, we briefly discuss the roles of cyanobacteria in the improvement of soil stability, soil nutrient and moisture status, organic matter content, microbial activities, and the growth and productivity of crops. Application of cyanobacteria is especially promising in croplands from dryland regions where high tolerance of these organisms to harsh environmental conditions converts them into viable alternatives or complements to more widespread conservation practices based on vegetation covers.
\end{abstract}

Keywords: Biocrust; Fertility; Carbon sequestration; Soil erosion; Cropland

\section{Introduction}

The increase of world's population and subsequent increase in food demand has led to a significant expansion of the cultivated land. Global cropland cover represents around 1370 million hectares or $12 \%$ of ice-free land [1]. Traditional agriculture including intensive tillage, removal of herbaceous cover, use of chemical fertilizers and pesticides have led to several environmental problems such as contamination of water bodies, damage to soil structure, accelerated oxidation of organic matter, loss of nutrients, high erosion rates, and loss of diversity [2]. Ultimately, these problems reduce the ability of the agro-system to provide vital ecosystem services and reduce the soil capacity for $\mathrm{C}$ sequestration [3]. It has been estimated an average SOC loss of $22 \%$ in 50 years due to agricultural erosion [4] and some scenarios predict that agriculture could become the main source of CO2 released in the atmosphere by 2050 (IIASA's Integrated Assessment Modeling Framework project). Effects could be even more dramatic in the Mediterranean basin, where the predicted increase in aridity [5] due to climatic change impacts are expected to have important consequences on crop productivity and will have direct social, economic and ecological consequences, such as increase in poverty and food insecurity, land degradation and depletion of natural resources [6]. As an example, an estimated 12 million hectares of agricultural land, which could potentially produce 20 million tons of grain, are lost every year due to land degradation. This urgently demands for interventions to transform current food production systems into sustainable and climateresilient systems that ensure food supply and at the same time that mitigate our impact on the Earth system. To sustain agricultural productivity and environmental quality, the presence of a healthy living soil with improved quality, able to support vegetation and microbial communities and to provide basic regulation services is required [7].

\section{Why cyanobacteria? Their role in the environment}

Cyanobacteria are prokaryotic oxygenic phototrophs, which have the ability to colonize very diverse environments thanks to their extraordinary resilience to stressful environmental conditions such as extremes of temperature, UV irradiance, drought, salinity and rapid hydration/dehydration cycles [8,9]. Cyanobacteria play a number of important roles in the environment [10] (Figure 1). Cyanobacteria increase soil stability and reduce erosion by water and wind [11], increase surface moisture by holding large amounts of water [12], and fix carbon $(\mathrm{C})$ and nitrogen $(\mathrm{N})$, thus 
increasing soil fertility (Figure 1) [13]. In arid and semiarid environments, cyanobacteria are one of the most important microorganisms forming biological soil crust communities [14], which are recognized to have major roles in hydrological, erosion, biogeochemical and ecological processes [15] and to provide critical services to society [16]. Due to these recognized roles, soil inoculation with cyanobacteria or cyanobacterisation is proposed as a sustainable technique to improve soil quality and combat degradation processes in drylands [17].

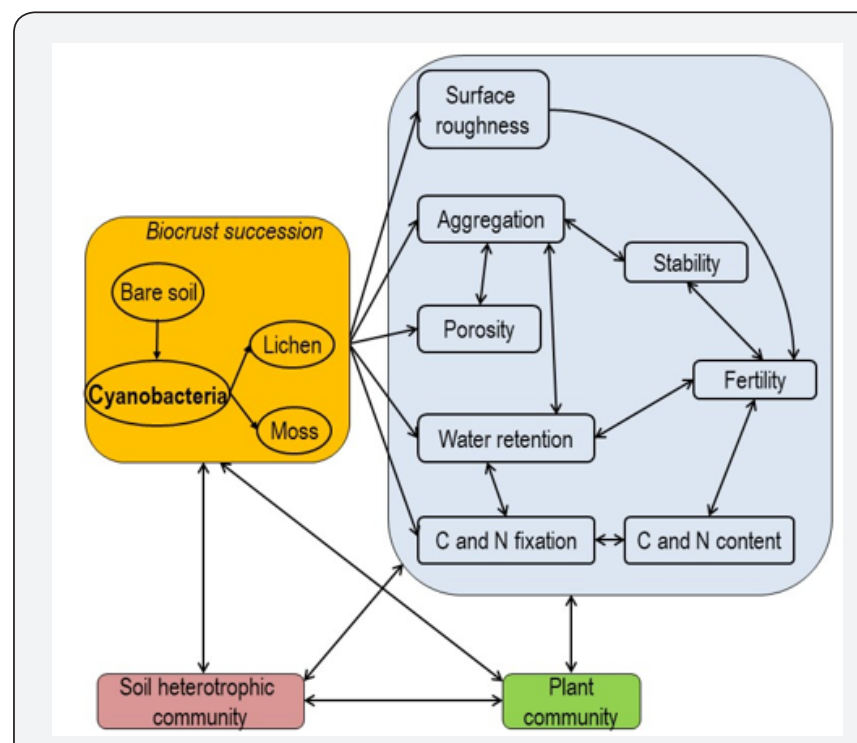

Figure 1: Scheme showing interactions among biocrusts, soil properties and soil and plant communities.

\section{Cyanobacteria for improvement of soil water status}

Cyanobacterial biocrusts are able to affect all components of the soil water balance (infiltration and runoff, evaporation, soil moisture, dewfall deposition) by modifying soil properties such as roughness, albedo, hydrophobicity, porosity and water retention [18-20]. In general, cyanobacteria increase water availability by increasing infiltration and maintaining surface moisture longer compared to bare soils [21]. Their role in soil moisture is largely due to the ability of polysaccharide sheaths to absorb up large amounts of water. Besides, exopolysaccharides can trap airborne particles, leading to the accretion of new sand and clay layers that increase the sorptivity of the soil helping water infiltration [22]. A stable soil moisture potential down to $20 \%$ water content has been found in natural crusts, while a decrease of soil moisture potential at $80 \%$ water content has been found after removal of cyanobacterial-EPS from the soil [12].

\section{Cyanobacteria as soil stabilization agents}

The importance of cyanobacteria in enhancing the stability of soil aggregates has been widely described [23]. This is especially significant within the first millimeters of the soil surface and strongly improving soil's resistance to both wind and water erosion $[11,18,24,25]$. Two are the main mechanisms of cyanobacteria for soil particle binding: i. Mechanically, by entangled filaments thus forming a network in the upper soil layers that greatly enhances aggregate stability;

ii. Chemically, by the sticky polysaccharides binding soil particles, and favouring soil aggregation [26].

Several studies have demonstrated enhanced aggregation when soils are inoculated with cyanobacteria $[25,27,28]$. This effect in soil stability has important implications on the reduction of water, sediment and nutrient losses by erosion and consequent effects in the reduction of water eutrophization, maintaining of fresh water pools, reduction of soil C losses and release of $\mathrm{CO} 2$ and other greenhouse gases to the atmosphere, thus improving soil $\mathrm{C}$ levels.

\section{Cyanobacteria as regulators of biogeochemical cycles}

Cyanobacteria also play important direct roles in $\mathrm{CO} 2$ fixation and Ccycling in soils. Cyanobacteria produce extracellular polymers of diverse chemical composition, especially exopolysaccharides that can represent $75 \%$ of the carbohydrates synthesized by biocrusts [13]. Organic matter is incorporated into the soil from the decay of cyanobacteria biomass and exopolysaccharides, thus also increasing the humus content. It has been shown the increase in soil organic $\mathrm{C}$ content after soil inoculation with cyanobacteria [29]. However, less studied has been the effect of cyanobacteria inoculation on soil CO2 fluxes. In a recent experiment in China, soils inoculated with cyanobacteria showed 3.3 times higher C fixation rates than non-inoculated soils [30].

Cyanobacteria, especially the $\mathrm{N}$-fixers cyanobacteria, increase the $\mathrm{N}$ content in natural desert soils. This fixed $\mathrm{N}$ is either released to the surrounding environment and make it available to plants [31], or either released to the atmosphere in the form of N20, or NO and HONO, which influence ozone and $\mathrm{OH}$ reactivity at the atmosphere [32]. Phosphorus is the second important nutrient after $\mathrm{N}$ for plants and microorganisms. Cyanobacteria influence the availability of $\mathrm{P}$ to plants as they have the ability to transform non-usable forms of inorganic-P to a usable form through biological processes [33]. Inoculation of the soil surface with different heterocystous and non-heterocystous cyanobacteria has been reported to enhance total N, available $\mathrm{N}$, and available P [34].

\section{Cyanobacteria as promoters of diversity and facilitators for other organism colonization}

Due to the improved effects on soil structure and stability, nutrient content and soil moisture availability, cyanobacteria improve the microhabitat for the soil heterotrophic community $[31,35,36]$ and facilitate the colonization of other organisms such as lichens and mosses, and the establishment and survival of annual and vascular plants in dry environments [37,38]. The enriched organic $\mathrm{C}$ substrate provided by cyanobacteria also becomes the support of a more abundant and diverse population of soil microfauna [39]. Hence, biocrusts, and especially welldeveloped ones as those dominated by cyanobacteria, are used as indicators of biodiversity and soil health [40]. 
Direct effects of cyanobacteria on plant growth from crops have been also reported due to the production of a great number of substances such as growth-promoting regulators, vitamins, amino acids, polypeptides, biotin, metabolites that act as allelochemical agents, proteins, total soluble sugars, antibacterial and antifungal substances that exert phytopathogen biocontrol, and polymers, especially exopolysaccharides that improve soil structure and exoenzyme activity [41].

\section{Use of cyanobacteria in agriculture: current and future perspectives}

Recent studies demonstrate the viability of inoculating soils with cyanobacteria (or cyanobacterisation) as a strategy to artificially induce the formation of a biocrust and combat desertification processes in drylands $[17,30]$. However, their use to reduce soil erosion and increase soil fertility and C sequestration in agricultural lands from drylands has been scarcely explored.

In the field of agriculture, cyanobacteria have been mainly used as biofertilizers due to their role as nutrient supplements [42]. Investigations have mainly focused on the use of aquatic species as for example Anabaena azollae in the fertilization of rice paddies throughout Asia [43]. To a much lesser extent, inoculation of diverse N-fixing cyanobacteria species as Nostoc, Calothrix, Tolypothrix, and Scytonema in non-waterlogged soils has also shown beneficial effects in terms of improvement of quality of soil properties and enhancement in plant growth in a number of crops such as tomato, wheat, maize, and lettuce $[44,45]$. Together with their recognized functions as natural fertilizers, cyanobacteria provide a number of ecological roles that open the range for their application in agriculture. The use of cyanobacteria in agricultural systems from drylands is especially promising given the extreme resistance that these organisms present to the abiotic stresses that characterize these regions such as low rainfall, high radiation levels and long periods of drought. Application of cyanobacteria in arid croplands is expected to have a major effect in the maintenance of adequate levels of soil organic matter, improvement of soil fertility and reduction of sediment and nutrient losses by water erosion, which is one of the most common processes accelerating soil degradation in agricultural lands from drylands. Besides, inoculation of soils with cyanobacteria can provide valuable solutions for sequestration of $\mathrm{CO} 2$ and other gases involved in global warming. So far, the use of vegetation covers has been the main conservation practice in rainfed and irrigated crops from drylands in order to combat soil degradation processes and prevent the mineralization of organic matter and the loss of soil structure and soil fertility in crops [46]. While these techniques are known to have an important effect on the increase of soil organic $\mathrm{C}$ levels, improvement of soil enzymatic activity and $\mathrm{CO} 2$ sequestering, they have the disadvantage of higher water requirements and, in some cases, competition for resources with crops. Application of cyanobacteria, isolated or in combination with cover crops, could provide very interesting results in terms of reduction of soil erosion and increase of soil fertility, at the same time that reduce water demands.
Up to now, there has been a low development of these techniques due to lack of knowledge regarding the factors involved in the success and failure of establishment of inoculated cyanobacteria under field conditions. Development of these sustainable biotechnological techniques requires efforts of both basic and applied research to move from laboratory or indoor conditions to their application in the field. Research involves the selection of suitable cyanobacteria species that ensures successful survival, establishment and performance in the field, as well as optimization of the conditions for cyanobacteria culture in order to maximize biomass productivity, while minimizing production costs. To this regard, it has been shown the possibility of culturing cyanobacteria using eutrophicated water sources as culture media to sequester the nitrates and phosphorus excess from polluted water and their subsequent recycling as biofertilizer for plant growth [47]. This would represent an extremely green lowcost technology, contributing on one hand to bioremediation of wastewaters and, on other hand, to supply one of the most limiting nutrients for crop productivity, i.e. P, as a biofertilizer. Efforts made in the last years have contributed to important advances in the application of cyanobacteria as inoculants for dryland soil restoration. Further research will allow broadening the range of applications, including their use to advance towards a more sustainable agriculture in the 21st century, especially challenging in dryland regions under current climate change context.

\section{Acknowledgement}

We want to acknowledge support from the European Union's Horizon 2020 research and innovation programme under the Marie Sklodowska-Curie grant agreement $\mathrm{N}^{\circ}$ 706351, Project Cyano4REST, and the Spanish National Plan for Research under the RESUCI Project (CGL2014-59946-R), also including European Union ERDF funds.

\section{References}

1. Han P, Zeng N, Zhao F, Lin X (2017) Estimating global cropland production from 1961 to 2010. Earth System Dynamics 8: 875-887.

2. Amundson R, Berhe AA, Hopmans JW, Olson C, Sztein AE, et al. (2015) Soil and human security in the 21st century. Science 348(6235).

3. Lal R (2002) Soil carbon dynamics in cropland and rangeland. Environmental Pollution 116(3): 353-362.

4. Doetterl S, van Oost K, Six J (2012) Towards constraining the magnitude of global agricultural sediment and soil organic carbon fluxes. Earth Surface Processes and Landforms 37: 642-655.

5. IPCC (2013) Annex I: Atlas of Global and Regional Climate Projections.

6. Beddington J, Asaduzzaman M, Fernandez A, Clark M, Guillou M, et al (2011) Achieving food security in the face of climate change: Summary for policy makers from the Commission on Sustainable Agriculture and Climate Change. CGIAR Research Program on Climate Change, Agriculture and Food Security (CCAFS). Copenhagen, Denmark.

7. Singh JS, Pandey VC, Singh DP (2011) Efficient soil microorganisms: A new dimension for sustainable agriculture and environmental development. Agriculture, Ecosystems \& Environment 140(3): 339353.

8. Rastogi RP, Sonani RR, Madamwar D (2014) The high-energy radiation protectant extracellular sheath pigment scytonemin and its reduced 
counterpart in the cyanobacterium Scytonema sp. R77DM. Bioresource Technology 171: 396-400.

9. Raanan H, Felde VJMNL, Peth S, Drahorad S, Ionescu D, et al. (2016) Three-dimensional structure and cyanobacterial activity within a desert biological soil crust. Environ Microbiol 18(2): 372-383.

10. Abed RMM, Dobretsov S, Sudesh K (2009) Applications of cyanobacteria in biotechnology. Journal of Applied Microbiology 106(1): 1-12.

11. Bowker MA, Belnap J, Chaudhary BV, Johnson NC (2008) Revisiting classic water erosion models in drylands: The strong impact of biological soil crusts. Soil Biology \& Biochemistry 40(9): 2309-2316.

12. Adessi A, de Carvalho CR, De Philippis R, Branquinho C, da Silva MJ (2018) Microbial extracellular polymeric substances improve water retention in dryland biological soil crusts. Soil Biology \& Biochemistry 116: 67-69.

13. Mager DM, Thomas AD (2011) Extracellular polysaccharides from cyanobacterial soil crusts: A review of their role in dryland soil processes. Journal of Arid Environments 75: 91-97.

14. Rodríguez-Caballero E, Belnap J, Büdel B, Crutzen PJ, Andreae MO, et al. (2018a) Dryland photoautotrophic soil surface communities endangered by global change. Nature Geoscience 11(3): 185-189.

15. Maestre FT, Bowker MA, Cantón Y, Castillo-Monroy AP, Cortina J, et al. (2011) Ecology and functional roles of biological soil crusts in semiarid ecosystems of Spain. Journal of Arid Environments 75: 1282-1291.

16. Rodríguez-Caballero E, Castro AJ, Chamizo S, Quintas-Soriano C, Garcia-Llorente M, et al. (2017) Ecosystem services provided by biocrusts: From ecosystem functions to social values. Journal of Arid Environments.

17. Rossi F, Li H, Liu Y, De Philippis R (2017) Cyanobacterial inoculation (cyanobacterisation): Perspectives for the development of a standardized multifunctional technology for soil fertilization and desertification reversal. Earth-Sciences Review 171: 28-43.

18. Rodríguez-Caballero E, Cantón Y, Chamizo S, Lázaro R, Escudero A (2013) Soil loss and runoff in semiarid ecosystems: a complex interaction between biological soil crusts, micro-topography, and hydrological drivers. Ecosystems 16(4): 529-546.

19. Chamizo S, Belnap J, Eldridge DJ, Cantón Y, Issa OM (2016a) The role of biocrusts in arid land hydrology. In: Weber B, Büdel B, et al. (Eds.), Biological soil crusts: An organizing principle in drylands, Ecological Studies 226, Springer International Publishing Switzerland, pp. 321346

20. Chamizo S, Cantón Y, Rodríguez-Caballero E, Domingo F (2016b) Biocrusts positively affect the soil water balance in semiarid ecosystems. Ecohydrology 9(7): 1208-1221.

21. Chamizo S, Cantón Y, Lázaro R, Domingo F (2013) The role of biological soil crusts in soil moisture dynamics in two semiarid ecosystems with contrasting soil textures. Journal of Hydrology 489: 74-84.

22. Rossi F, Potrafka RM, Garcia-Pichel F, De Philippis R (2012) The role of the exopolysaccharides in enhancing hydraulic conductivity of biological soil crusts. Soil Biology \& Biochemistry 46: 33-40.

23. Chamizo S, Cantón Y, Miralles I, Domingo F (2012) Biological soil crust development affects physicochemical characteristics of soil surface in semiarid ecosystems. Soil Biology \& Biochemistry 49: 96-105.

24. Knapen A, Poesen J, Galindo-Morales P, Baets SD, Pals A (2007) Effects of microbiotic crusts under cropland in temperate environments on soil erodibility during concentrated flow. Earth Surface Processes and Landforms 32(12): 1884-1901.

25. Chamizo S, Mugnai G, Rossi F, Certini G, De Philippis R (2018) Cyanobacteria Inoculation Improves Soil Stability and Fertility on Different Textured Soils: Gaining Insights for Applicability in Soil Restoration. Frontiers in Environmental Science 6(49).
26. Mazor G, Kidron GJ, Vanshak A, Abeliovich A (1996) The role of cyanobacterial exopolysaccharides in structuring desert microbial crusts. FEMS Microbiology Ecology 21(2): 121-130.

27. McKenna NC, Maxwell CD, Boulton JW (1996) Wind transport of sand surfaces crusted with photoautotrophic microorganisms. Catena 27(34): 229-247

28.Xie Z, Liu Y, Hu C, Chen L, Li D (2007) Relationships between the biomass of algal crusts in fields and their compressive strength. Soil Biology \& Biochemistry 39(2): 567-572.

29. Román-Fernández R, Roncero-Ramos B, Chamizo S, RodríguezCaballero E, Cantón Y (2018) Restoring soil functions by means of cyanobacteria inoculation: importance of soil conditions and species selection. Land Degradation \& Development.

30. Park CH, Li XR, Zhao Y, Jia RL, Hur JS (2017) Rapid development of cyanobacterial crust in the field for combating desertification. PLoS ONE 12(6).

31. Delgado-Baquerizo M, Morillas L, Maestre FT, Gallardo A (2013) Biocrusts control the nitrogen dynamics and microbial functional diversity of semi-arid soils in response to nutrient additions. Plant and Soil 372(1-2): 643-654.

32. Weber B, Wu D, Tamm A, Ruckteschler N, Rodríguez-Caballero E, et al. (2015) Biological soil crusts accelerate the nitrogen cycle through large NO and HONO emissions in drylands. Proceedings of the National Academy of Sciences 112(50): 15384.

33. Zhang GX, Zhao YG, Xu MX, Gao LQ (2012) Impacts of biological soil crust on availability of phosphorus and phosphatase activity in hilly regions of the Loess Plateau, China. Plant Nutrition and Fertilizer Science 18: 621-628.

34. Wu Y, Rao B, Wu P, Liu Y, Li G, et al. (2013) Development of artificially induced biological soil crusts in fields and their effects on top soil. Plant Soil 370: 115-124.

35. Chen L, Rossi F, Deng S, Liu Y, Wang G, et al. (2014) Macromolecular and chemical features of the excreted extracellular polysaccharides in induced biological soil crusts of different ages. Soil Biology \& Biochemistry 78: 1-9.

36. Maier S, Tamm A, Wu D, Caesar J, Grube M, et al. (2018) Photoautotrophic organisms control microbial abundance, diversity, and physiology in different types of biological soil crusts. The ISME Journal 12(4): 10321046.

37. Lan S, Wu L, Zhang D, Hu C (2013) Assessing level of development and successional stages in biological soil crusts with biological indicators. Microbial Ecology 66(2): 394-403.

38. Rodríguez-Caballero E, Chamizo S, Roncero-Ramos B, Román $\mathrm{R}$, Cantón Y (2018) Runoff from biocrust: A vital resource for vegetation performance on Mediterranean steppes. Ecohydrology pp. e1977.

39. Darby BJ, Neher DA, Belnap J (2007) Soil nematode communities are ecologically more mature beneath late- than early-successional stage biological soil crusts. Applied Soil Ecology 35: 203-212.

40. Bowker MA, Maestre FT, Escolar C (2010) Biological crusts as a model system for examining the biodiversity-ecosystem function relationship in soils. Soil Biology \& Biochemistry 42(3): 405-417.

41. Gupta V, Ratha SK, Sood A, Chaudhary V, Prasanna R (2013) New insights into the biodiversity and applications of cyanobacteria (bluegreen algae) - Prospects and challenges. Algal Research 2(2): 79-97.

42. Sharma R, Khokhar MK, Jat RL, Khandelwal SK (2012) Role of algae and cyanobacteria in sustainable agriculture system. Wudpecker Journal of Agricultural Research 1: 381-388.

43. Priya H, Prasanna R, Ramakrishnan B, Bidyarani N, Babu S, et al. (2015) Influence of cyanobacterial inoculation on the culturable microbiome and growth of rice. Microbiol Res 171: 78-89. 
44. Thajuddin N, Subramanian G (2005) Cyanobacterial biodiversity and potential applications in biotechnology. Current Science 89(1): 47-57.

45. Maqubela MP, Muchaonyerwa P, Mnkeni PNS (2012) Inoculation effects of two South African cyanobacteria strains on aggregate stability of a silt loam soil. African Journal of Biotechnology 11(47): 10726-10735.

46. Márquez-García F, Gonzalez-Sanchez EJ, Castro-Garcia S, OrdoñezFernandez R (2013) Improvement of soil carbon sink by cover crops in olive orchards under semiarid conditions. Influence of the type of soil and weed. J Agric Res 11: 335-346.

47. Mukherjee C, Chowdhury R, Ray K (2015) Phosphorus Recycling from an Unexplored Source by Polyphosphate Accumulating Microalgae and Cyanobacteria - A Step to Phosphorus Security in Agriculture. Frontiers in Microbiology 6(1421).

\section{Your next submission with Juniper Publishers will reach you the below assets}

- Quality Editorial service

- Swift Peer Review

- Reprints availability

- E-prints Service

- Manuscript Podcast for convenient understanding

- Global attainment for your research

- Manuscript accessibility in different formats

( Pdf, E-pub, Full Text, Audio)

- Unceasing customer service

Track the below URL for one-step submission https://juniperpublishers.com/online-submission.php 